\title{
Is there an epidemic of HIV/AIDS among heterosexuals in the USA?
}

\author{
H W Haverkos, R C Chung, L C Norville Perez
}

Postgrad Med J 2003;79:444-448

The Centers for Disease Control and Prevention (CDC), Atlanta, reports HIV infections and AIDS cases in the United States biannually. Trends in the distribution of HIV/AIDS cases according to sex, race or ethnic group, and various categories of exposure to HIV were analysed. The groups in which there were the greatest percentage increases over time were the group with heterosexual contact and the group for whom the risk factors were not reported or identified. The CDC should be encouraged to provide additional information regarding sexual and drug-using behaviours of those patients listed as "undetermined".

See end of article for authors' affiliations

Correspondence: Dr Harry W Haverkos, HFD-530, 5600 Fishers Lane, Rockville, MD, 20857 USA; haverkosh@ cder.fda.gov

Submitted 13 August 2002 Accepted 8 April 2003
5 ew issues related to AIDS have generated as much interest and debate in the USA as heterosexual transmission of HIV and its potential importance to the epidemic. In the book Crisis: Heterosexual Behavior in the Age of AIDS published in 1988, sex therapists Masters et al screened 3805 men and women in Atlanta, Los Angeles, New York, and St Louis, and observed that HIV had spread among heterosexual American adults. ${ }^{1}$ In 1990, civil rights journalist Michael Fumento published The Myth of Heterosexual AIDS and suggested that the US Public Health Service was exaggerating the epidemic among heterosexuals to garner increased research funds. ${ }^{2}$ In a 1988 proportion of cases attributed to heterosexual transmission had not increased relative to other risk groups. ${ }^{3}$ Where is the HIV/AIDS epidemic going in the USA in the 21 st century? What can be learned from the Centers for Disease Control and Prevention (CDC) surveillance data for AIDS and HIV infection?

\section{METHODS}

Since 1981, the CDC has tabulated and reported AIDS cases in the USA and listed patients by exposure categories. Since 1993, the CDC has tabulated and reported HIV infection not AIDS, in those states and territories willing to report such data. We analysed CDC HIV/AIDS surveillance year end reports from 1983 to 2001, examining changes in the definitions of exposure categories, and trends in the incidence of AIDS cases and HIV infections as reported. ${ }^{4}$

Using the CDC hierarchical definition of exposure categories, we constructed five mutually exclusive categories among adults/adolescents. First, "gay" men or men who have sex with men review article on the epidemiology of AIDS, the includes all males over the age of 13 years at diagnosis who reported any sex with males and includes those who also reported having injected drugs not prescribed by a physician. Second, injection drug users includes both men who deny sex with men and females who reported ever injecting drugs not prescribed by a physician. Third, blood transfusion recipients include adults and adolescents who deny male homosexuality and injection drug abuse and have been a recipient of whole blood, blood components, or tissues. Blood recipients also included persons with haemophilia and coagulation disorders who have received fractionation proteins. Fourth, heterosexual contact cases are defined as those who deny male homosexuality, injection drug use, and receipt of any blood products and reported heterosexual contact with a person with HIV/ AIDS or at increased "risk" for HIV/AIDS. "Risk" is defined as men who have sex with men, injection drug users, or blood recipients. Fifth, "undetermined" or risk not specified refers to all other patients whose mode is unknown or not clearly specified. This undetermined group includes patients under investigations, who died, were lost to follow up, or refused interview, and patients not meeting a risk category definition listed above after interview. Heterosexual contact patients were further subdivided by the reported risk of the identified sexual partner, or if a partner was not identified as a bisexual man, injection drug user, or blood transfusion recipient, those heterosexual contact patients are listed as having sex with a partner of "undetermined risk" with HIV/ AIDS. Children, all patients less than 13 years of age at HIV or AIDS diagnosis are listed without regard to exposure category. We tabulated data by gender, racial or ethnic group, and exposure category for AIDS cases from 1981-2001, and HIV infection from 1993-2001, charting the total numbers of reported patients and percentages of exposure categories.

\section{RESULTS}

Table 1 lists the number of patients with AIDS reported each year from 1983-2001; the number of HIV infections, without AIDS, reported each year, and numbers of states/US territories reporting HIV infection from 1993-2001. ${ }^{4}$ The definition of AIDS for case reporting expanded several times, including the inclusion of additional opportunistic infections in 1987 and to include additional diagnoses and laboratory indicators of immunodeficiency in 1993. ${ }^{5-8}$ The 1993 change in the case definition of AIDS, the increasing use of highly active antiretroviral therapy for HIV infected persons, and the increasing number of 
Table 1 AIDS and HIV cases reported by the CDC from 1981 to December 2001, United States

\begin{tabular}{llll}
\hline Year & No with AIDS & $\begin{array}{l}\text { No with HIV infection, not } \\
\text { AIDS }\end{array}$ & $\begin{array}{l}\text { No of states/territories reporting } \\
\text { HIV infection }\end{array}$ \\
\hline $1981-1983$ & 3064 & 0 & 0 \\
1984 & 4530 & 0 & 0 \\
1985 & 8354 & 0 & 0 \\
1986 & 13097 & 0 & 0 \\
1987 & 20620 & 0 & 0 \\
1988 & 32311 & 0 & 0 \\
1989 & 35238 & 0 & 0 \\
1990 & 43339 & 0 & 0 \\
1991 & 45506 & 0 & 0 \\
1992 & 47106 & 0 & 0 \\
1993 & 106949 & 15047 & 26 \\
1994 & 80691 & 18598 & 27 \\
1995 & 74180 & 15206 & 28 \\
1996 & 69151 & 13769 & 30 \\
1997 & 60634 & 14514 & 30 \\
1998 & 48269 & 19391 & 33 \\
1999 & 46400 & 21417 & 34 \\
2000 & 42156 & 21704 & 36 \\
2001 & 43150 & 35575 & 39 \\
Total & 816149 & 174026 & - \\
\hline Source: reference & 4 & & \\
\hline
\end{tabular}

Table 2 Cases of AIDS reported in USA in 1986, 1991, 1996, and 2001 according to category of exposure

\begin{tabular}{llllll}
\hline Exposure category & 1986 & 1991 & 1996 & 2001 & \% Change* \\
\hline Adult/adolescent & & & & & \\
$\quad$ 1. Gay men & $9416(72)$ & $26326(58)$ & $30283(44)$ & $14767(34)$ & -38 \\
2. Injecting drug users & $2136(16)$ & $11155(25)$ & $17027(25)$ & $7473(17)$ & +1 \\
3. Blood recipients & $405(3)$ & $1030(2)$ & $869(1)$ & $324(1)$ & -2 \\
4. Heterosexual contact & $485(4)$ & $3387(8)$ & $8821(13)$ & $6904(16)$ & +12 \\
5. Undetermined & $468(4)$ & $2925(7)$ & $11473(17)$ & $13515(31)$ & +27 \\
Children & $187(1)$ & $683(2)$ & $678(1)$ & $175(0)$ & -1 \\
Total & $13097(100)$ & $45506(100)$ & $69151(100)$ & $43158(100)$ & - \\
\hline
\end{tabular}

Source: reference 4 .

* Percent change calculated by subtracting \% in 1986 from \% in 2001 .

Notes: See text for definitions of exposure categories.

1. Gay men include all men who report sex with men and those men who also report injecting drug use.

2. Injecting drug users excluding men who have sex with men.

3. Blood recipients include adults/adolescents who deny male homosexual behaviour and injecting drug use, and are haemophiliac or transfusion recipients of blood or blood components.

4. Heterosexual contact include adults/adolescent who deny male homosexual behaviour, injecting drug use, haemophilia, and previous blood or blood components, and report heterosexual contact with a person with

HIV or AIDS, a bisexual male, injecting drug user or blood recipient.

5. Undetermined includes patients who do not meet any of the definitions above (see text).

Children include all those under age 13 years at time of diagnosis regardless of exposure category.

states/territories reporting HIV infection complicate the interpretation of surveillance data.

The classification schema to count AIDS patients by exposure categories has been modified by CDC as clinicians and epidemiologists learned more about the epidemiology of HIV transmission, however exposure categories have always been listed hierarchically. Patients with multiple characteristics are tabulated in the group listed first. The definition of heterosexual contact and undetermined patients changed several times between 1984 and 1989, and has remained the same since 1989. Heterosexual contact patients were first reported in 1984 and included those who denied male homosexuality, intravenous drug use, Haitian origin, or haemophilia and reported heterosexual contact with a person with AIDS or at risk for AIDS. In 1985, the Haitian category was incorporated into heterosexual contact patients if such patients reported sex with a person with AIDS or at risk for AIDS. Haitian patients not reporting sex with a person with AIDS or at risk for AIDS were listed as "None of the above/other"/“as persons born in countries in which most AIDS cases have not been associated with known risk factors". ${ }^{4}$ In 1986, the "None of the above/other" category was renamed "Undetermined". Undetermined included "patients on whom risk information is incomplete (due to death, refusal to be interviewed, or loss to follow up), patients still under investigation, men reported only [italics added] to have had heterosexual contact with a prostitute, and interviewed patients for whom no specific risk was identified". In 1989, the CDC acknowledged that some of these "undetermined" patients may represent "unrecognised" heterosexual transmission of HIV.

Table 2 lists the reported patients with AIDS according to exposure categories in 1986, 1991, 1996, and 2001. Homosexual or bisexual men, including those gay men who injected drugs, accounted for $72 \%$ of all cases reported in 1986 and 34\% in 2001. The groups in which there were the greatest percentage increases over time were the group with heterosexual contact category $(4 \%-16 \%)$ and the group for whom risk 
Table 3 Heterosexual contact cases of AIDS reported in USA in 1988, 1991, 1996 , and 2001 by attributed partner source exposure category

\begin{tabular}{|c|c|c|c|c|c|}
\hline $\begin{array}{l}\text { Heterosexual by identified } \\
\text { partner source }\end{array}$ & 1988* & 1991 & 1996 & 2001 & $\%$ Change* \\
\hline With bisexual male & $88(6)$ & $147(4)$ & $306(3)$ & $192(3)$ & -3 \\
\hline With injecting drug user & $847(55)$ & $1798(53)$ & $2790(32)$ & $1486(22)$ & -33 \\
\hline With blood recipient & $39(3)$ & $108(3)$ & $148(2)$ & $45(1)$ & -2 \\
\hline Born in pattern- 2 countryt & $379(25)$ & $510(15)$ & - & - & - \\
\hline $\begin{array}{l}\text { Sex with person born in } \\
\text { pattern- } 2 \text { country }\end{array}$ & $21(1)$ & $44(1)$ & - & - & - \\
\hline With undetermined & $167(11)$ & $780(23)$ & $5577(63)$ & $5181(75)$ & $\begin{array}{l}\text { Calculation is not } \\
\text { appropriate due to } \\
\text { definition changes }\end{array}$ \\
\hline Total & $1541(100)$ & $3387(100)$ & $8821(100)$ & $6904(100)$ & - \\
\hline \multicolumn{6}{|c|}{$\begin{array}{l}\text { Source: reference } 4 . \\
\text { * } 1988 \text { was the first year that CDC reported the number of heterosexual contact cases further subdivided by } \\
\text { identified partner source. } \\
\text { tPattern- } 2 \text { was observed in areas of central, eastern, and southern Africa and in some Caribbean countries } \\
\text { In those countries, most of the reported cases occur in heterosexuals; the male-to-female ratio is } \\
\text { approximately } 1: 1 \text {; and perinatal transmission is more common than in other areas. CDC stopped reporting } \\
\text { patients by birth in pattern- } 2 \text { countries in } 1993 \text { (see text and reference } 4 \text { ). }\end{array}$} \\
\hline
\end{tabular}

factors were not reported or identified $(4 \%-31 \%)$. Furthermore, a shift or movement of AIDS into the heterosexual community is suggested by evaluating the trends in proportions of the "risk identified for partners" of heterosexual transmission patients (table 3). Fifty five percent of heterosexual contact patients identified injection drug users as their partner source in $1988,22 \%$ in 2001 . Eleven percent of heterosexual contact patients reported source partners with undetermined HIV or AIDS risk in 1988, 75\% in 2001.

Investigators conducting AIDS surveillance have been criticised because AIDS represents the most advanced stages of HIV infection. HIV infection progresses to AIDS after a long incubation period, in many cases as long as 10 years or more after HIV infection. Highly active antiretroviral therapies became available in the mid-1990s and may further delay the progression of HIV infection to AIDS..$^{10}$ In 1993 CDC began reporting data from a number of states and territories on persons reported with HIV infection who have not yet developed AIDS (table 1). By December 1993, 26 states had laws or regulations requiring confidential reporting by name of persons with confirmed HIV infection (1993 report $\left.{ }^{4}\right)$. By December 2001, 35 states, American Samoa, Guam, Mariana Islands, and the Virgin Islands had such laws or regulations. New York State first reported HIV data in June 2000 and accounts for the increase in the HIV infections in 2001 (table 1). The data for HIV infection (not AIDS) shows similar trends as that reported for AIDS. ${ }^{4}$ For example, $36 \%$ of all new HIV infections reported in 1993 were among gay men, $23 \%$ in 2001 . Undetermined cases accounted for $29 \%$ of reported HIV infections in $1993,54 \%$ in 2001 (data not shown).

The heterosexual HIV and AIDS epidemics in the USA have occurred predominantly in the African-American and Hispanic populations. ${ }^{11}$ Table 4 shows the number of AIDS cases of selected exposure categories by gender and race/ethnicity reported in 1991, 1996, and 2001.

\section{DISCUSSION}

We have reviewed AIDS and HIV surveillance data collected by CDC. These data demonstrate a shift of the epidemic from "gay" men and injection drug users to heterosexual contacts and those in the "undetermined" category. We also consider these data supportive of the hypothesis that primary transmission from "high risk" group members to heterosexual contacts continues to occur and that secondary and tertiary transmission from heterosexuals of "lower risk" to others is occurring and increasing.

There are several surveillance research issues raised by these data. The most obvious is to interpret cases of HIV and AIDS among those in the "undetermined" category. The AIDS risk classification system evolved into a hierarchical system based on reports of risk in the 1980s. This system evolved as new groups were identified with AIDS- that is, "gay" men, injecting drug users, Haitian-Americans, haemophiliacs, blood transfusion recipients, heterosexual men and women, health care workers. This system was effective at understanding routes of transmission, even before an aetiological agent was identified. However, the rationale for a hierarchical system no longer exists and creates a systematic bias in estimating HIV transmission among heterosexuals, who are at the lowest level of the system.

The current definition of "heterosexual contact" cases is too restrictive and leads to a gross underestimation of heterosexual transmission of HIV in the USA. A heterosexual contact patient is currently defined as a person who denies other risk factors-that is, homosexuality, injecting drug use, blood recipient, and has had heterosexual contact with a person with HIV infection or AIDS or at risk for AIDS- that is, male homosexual, injecting drug user, blood transfusion recipient. All other cases among self reported heterosexuals not meeting this definition are placed in the undetermined category. This includes an unknown, but apparently growing, number of women who report prostitution (commercial sex work) or multiple heterosexual partners, but cannot or will not identify a sexual contact with HIV or AIDS. Similarly, an unknown number of men who report multiple sexual contacts, including contacts with commercial sex workers, and/or a history of one or more sexually transmitted diseases, are currently listed in the undetermined group. Several states, that is, Massachusetts, New York, Virginia, have developed a separate category, "presumed heterosexual transmission", to distinguish those cases likely to be transmitted heterosexually from those in which data are not available, due to death or refusal to be interviewed. CDC should take the lead in defining and reporting sexual transmission data in this burgeoning group of patients, currently listed as "undetermined".

There appears to be at least two separate and unequal epidemics in the USA segregated by race and sexual orientation. The initial outbreak occurred among gay, predominantly white men, exploded rapidly across urban areas of the USA, and appears now to be decreasing. A later epidemic arose within the heterosexual, predominantly African-American community, initially fuelled by heterosexual injecting drug users, and concentrated in the southern USA. ${ }^{11}$ The increasing number and proportion of African-American men and women in the "undetermined" category may underestimate the heterosexual nature of the latter epidemic. 
Table 4 AIDS cases according to gender and race/ethnicity of selected exposure categories in USA, 1991, 1996, and 2001

\begin{tabular}{|c|c|c|c|c|}
\hline & $\begin{array}{l}1991 \text { (cumulative) } \\
\text { No }(\%)\end{array}$ & $\begin{array}{l}1996 \\
\text { No }(\%)\end{array}$ & $\begin{array}{l}2001 \\
\text { No (\%) }\end{array}$ & $\%$ Change \\
\hline Total (all cases) & 206392 & 69151 & 43158 & - \\
\hline All males & 183569 (89) & $54997(80)$ & $31994(74)$ & -15 \\
\hline All females & $22823(11)$ & 14154 (20) & $11164(26)$ & +15 \\
\hline Males* & 181696 & 54653 & 31901 & \\
\hline White & 104180 (57) & 23341 (43) & 11164 (35) & -21 \\
\hline Black & $47037(26)$ & 20199 (37) & 13895 (44) & +17 \\
\hline Hispanic & $28624(16)$ & 10337 (19) & $6289(20)$ & +4 \\
\hline Other & 1422 (1) & 646 (1) & $510(2)$ & +1 \\
\hline Females* & 21225 & 13820 & 11082 & \\
\hline White & $5466(26)$ & $2888(21)$ & $2040(18)$ & -8 \\
\hline Black & $11156(53)$ & 8147 (59) & 7023 (63) & +10 \\
\hline Hispanic & 4400 (21) & 2629 (19) & 1894 (17) & -4 \\
\hline Other & 150 (1) & 122 (1) & 111 (1) & 0 \\
\hline Gay male & 131497 & 30283 & 14767 & \\
\hline White & 90572 (69) & $17719(59)$ & $7427(50)$ & -19 \\
\hline Black & 24118 (18) & $7689(25)$ & 4605 (31) & +13 \\
\hline Hispanic & 15165 (12) & 4386 (14) & 2433 (16) & +4 \\
\hline Other & $1177(1)$ & 439 (1) & $283(2)$ & +1 \\
\hline IDU: male & 35048 & 12333 & 7280 & \\
\hline White & $7017(20)$ & $2530(21)$ & $1281(18)$ & -2 \\
\hline Black & $16798(48)$ & 6349 (51) & 4049 (56) & +8 \\
\hline Hispanic & 11083 (32) & 3377 (27) & $1857(26)$ & -6 \\
\hline Other & $73(0)$ & $57(0)$ & $85(1)$ & +1 \\
\hline IDU: female & 10705 & 4694 & 3410 & \\
\hline White & $2268(21)$ & 1105 (24) & 660 (19) & -2 \\
\hline Black & 6185 (58) & $2713(58)$ & $2106(62)$ & +4 \\
\hline Hispanic & $2191(20)$ & 845 (18) & $618(18)$ & -2 \\
\hline Other & $41(0)$ & $25(1)$ & $24(1)$ & +1 \\
\hline Heterosexual contact: female & 7249 & 5522 & 4142 & \\
\hline White & $1700(23)$ & $1165(21)$ & 707 (17) & -6 \\
\hline Black & $3784(52)$ & $3038(55)$ & $2606(63)$ & +11 \\
\hline Hispanic & $1694(23)$ & $1257(23)$ & 781 (19) & -4 \\
\hline Other & $47(1)$ & $52(1)$ & $42(1)$ & 0 \\
\hline Heterosexual contact: male & 4687 & 3299 & 2762 & \\
\hline White & 813 (17) & $609(18)$ & 403 (15) & -2 \\
\hline Black & 3307 (71) & $1871(57)$ & $1705(62)$ & -9 \\
\hline Hispanic & $548(12)$ & $785(24)$ & $613(22)$ & +10 \\
\hline Other & $12(0)$ & $30(1)$ & $39(1)$ & +1 \\
\hline Undetermined: male & 6114 & 8159 & 8909 & \\
\hline White & 2287 (37) & $2130(26)$ & $2051(23)$ & -14 \\
\hline Black & 2269 (37) & 4152 (51) & 4803 (54) & +17 \\
\hline Hispanic & $1432(23)$ & $1713(21)$ & $1896(21)$ & -2 \\
\hline Other & $78(1)$ & $107(1)$ & $140(2)$ & +1 \\
\hline Undetermined: female & 1561 & 3317 & 4606 & \\
\hline White & 414 (27) & $537(16)$ & 727 (16) & -11 \\
\hline Black & $828(53)$ & $2256(68)$ & $3086(67)$ & +14 \\
\hline Hispanic & 292 (19) & $476(14)$ & $740(16)$ & -3 \\
\hline Other & $22(1)$ & $30(1)$ & 45 (1) & 0 \\
\hline Children & 3471 & 678 & 175 & \\
\hline White & $739(21)$ & $98(14)$ & 33 (19) & -2 \\
\hline Black & $1844(53)$ & $429(63)$ & $113(65)$ & +12 \\
\hline Hispanic & $854(25)$ & $145(21)$ & $26(15)$ & -10 \\
\hline Other & $25(1)$ & $4(1)$ & $3(2)$ & +1 \\
\hline
\end{tabular}

Source: reference 4. IDU, injection drug user.

Notes: 1993 was the first year that CDC reported the annual incidence of AIDS cases by exposure

categories further subdivided by race. Cumulative numbers from 1981-91 reported in 1991 column.

tPercent change was calculated by subtracting percent of subgroup in 1991 from percent of subgroup in 2001.

*Includes only those patients $>13$ years of age at diagnosis (adolescents/adults).

(A) White includes whites, non-Hispanic.

(B) Black includes African-Americans, non-Hispanic.

(C) Other includes Asians, Pacific Islanders, American Indians, and Alaska natives.

(D) Gay male includes men who have sex with men and men who have sex with men and inject drugs.

(E) Numbers do not always add due to missing data.

In summary, heterosexual transmission of HIV and AIDS appears to be increasing in the USA and may be grossly underestimated by our present surveillance system. An insidious epidemic can be identified within the African-American heterosexual community that demands immediate attention. The increasing proportion of "undetermined" transmission may represent a large number of heterosexual cases that are not counted as such. The importance of recognising the true incidence and prevalence of HIV infection and AIDS among heterosexuals is a public health issue. The under-estimation of the heterosexual transmission rate falsely reassures the public and may actually increase the likelihood of HIV infection and AIDS in the general population over the next several decades.

\section{ACKNOWLEDGEMENTS}

We thank Drs Lynne Haverkos, James Curran, Michael Greenspan, Stanka Kukich, Stefano Lazzari, Fred Payne, and Robert Remis for reviewing a draft manuscript and providing comments. 


\section{Key points}

- The proportions of patients with incident HIV infection and AIDS are increasing among heterosexuals and "undetermined risk", and decreasing among homosexual/bisexual men in the USA.

- The majority of HIV/AIDS patients attributed to heterosexual transmission, injecting drug use, vertical transmission, and "undetermined risk" are African-American. The majority of all female patients are African-American.

- The CDC hierarchical schema for determining HIV/AIDS exposures should be reviewed by those who interpret surveillance data for the public. The CDC definition for "heterosexual contact" exposure is too restrictive.

The opinion or assertions contained herein are the private views of the authors and are not to be construed as official or as reflecting the views of the Department of the Army, the Department of Defense, or the Food and Drug Administration.

\section{Authors' affiliations}

H W Haverkos, Infectious Disease Service, Department of Medicine, Walter Reed Army Medical Center, Washington, DC, USA

R C Chung, Division of Infectious Diseases, University of Texas Health Science Center at San Antonio, Texas, USA

L C Norville Perez, National Medical Association, Bethesda, Maryland, USA

\section{REFERENCES}

1 Masters WH, Johnson VE, Kolodny RC. Crisis: heterosexual behavior in the age of AIDS. New York: Grove Press, 1988.
2 Fumento $M$. The myth of heterosexual aids: how a tragedy has been distorted by the media and partisan politics. New York: New Republic, 1990.

3 Haverkos HW, Edelman R. The epidemiology of AIDS among heterosexuals. JAMA 1988;260: 1922-9

4 Centers for Disease Control and Prevention. HIV/AIDS Surveillance report, year end editions. 22 December 1983; 24 December 1984; 30 December 1985; 29 December 1986; 28 December 1987; issued January 1989; issued January 1990; issued January 1991; issued January 1989; issued January 1990; issued January 1991; issued 1995; 7(No 2); 1996;8(No 2); 1997;9(No 2); 1998;10(No 2); 1999;11(No 2); 2000;12(No 2); and 2001;13(No 2). Atlanta, Georgia: Centers for Disease Control and Prevention, Department of Health and Human Services (DHHS).

5 Centers for Disease Control and Prevention. Revision of the case definition of acquired immunodeficiency syndrome for national reporting MMWR Morb Mortal Wkly Rep 1985;34:373-5

6 Centers for Disease Control and Prevention. Revision of the CDC surveillance case definition for acquired immunodeficiency syndrome. Council of State and Territorial Epidemiologists; AIDS Program, Center for Infectious Diseases. MMWR Morb Mortal Wkly Rep 1987;36/suppl 1): 1S-15S.

7 Centers for Disease Control and Prevention. 1993 revised classification system for HIV infection and expanded surveillance case definition for AIDS among adolescents and adults. MMWR Morbid Mortal Wkly Rep 1992;41 (No RR-17): 1-19.

8 Centers for Disease Control and Prevention. Update: impact of the expanded AIDS surveillance case definition for adolescents and adults on case reporting-United States, 1993. MMWR Morb Mortal Wkly Rep 1994;43:160-1, 167-70.

9 Centers for Disease Control and Prevention. Update: heterosexual transmission of acquired immunodeficiency syndrome and human immunodeficiency virus infection-United States. MMWR Morb Mortal Wkly Rep 1989:38:423-34

10 Gostin LO, Ward JW, Baker AC. National HIV case reporting for the United States. A defining moment in the history of the epidemic. N Engl J Med 1997;337: 1152-7.

11 Haverkos HW, Turner JF, Moolchan ET, et al. Relative rates of AIDS among racial/ethnic groups by exposure categories. J Natl Med Assoc 1999:91:17-24. 